\title{
La inmigración latinoamericana y su influencia en la sociedad ecuatoriana de la provincia de Santa Elena
}

\section{Latin American immigration and its influence on Ecuadorian society in the province of Santa Elena}

Braulio Javier Toapanta Ulcuango. ${ }^{1,}$,Welinton Cristóbal Merino Narváez. ${ }^{2}$ \& Fatina Eugenia Campos Cárdenas. ${ }^{3}$ Asdrúbal Bayardo Merino Narvaez. ${ }^{4}$

Recibido: 22-03-2019 / Revisado: 27-04-2019 /Aceptado: 26-05-2019/ Publicado: 05-06-2019

\begin{abstract}
.
DOI: https://doi.org/10.33262/cienciadigital.v3i2.6.526

The objective of the research is to analyze the causes and consequences of the immigration of Latin American countries in the Ecuadorian society of Santa Elena province, especially immigrants from Venezuela, Colombia, Peru, Argentina and Chile, economic inflation is the main cause for there to be immigration with very high rates, the consequences of immigration are the lack of employment, housing, education and food for Ecuadorians, because the jobs are being covered by immigrants and with very low salaries. Among the Ecuadorian cities where immigrants arrive with a high percentage is Quito, Guayaquil, Cuenca, Oro, Santo Domingo and others.
\end{abstract}

Key words: Immigration, Latin American, Inflation, Economic, And Housing.

\section{Resumen}

La investigación a realizarse tiene como objetivo analizar las causas y consecuencias que generar la inmigración de los países latinoamericanos en la sociedad ecuatoriana de la provincia de Santa Elena, en especial los inmigrantes de Venezuela, Colombia, Perú, argentina y chile, la inflación económica es la causa principal para que exista una inmigración con índice muy altos, las consecuencias de la inmigración son la falta de empleo, vivienda, educación y alimentación para los ecuatorianos, porque la plazas laborales están siendo cubiertas por los inmigrantes y con sueldos muy

\footnotetext{
1 Unidad educativa Fuerzas Armadas COMIL, Quito, Ecuador.braulio.toapanta@educacion.gob.ec

2 Universidad de las Fuerzas Armadas ESPE, Quito, Ecuador, wcmerino@espe.edu.ec

${ }^{3}$ Universidad de las Fuerzas Armadas ESPE, Quito, Ecuador, fecampos1@espe.edu.ec

${ }^{4}$ Institución educativa Juan Pio Montufar, Quito, Ecuador, asdru123@hotmail.com.
} 
reducidos. Entre las ciudades ecuatorianas a donde llegan los inmigrantes con alto porcentaje es Quito, Guayaquil, Cuenca, Oro, Santo Domingo y otras.

Palabras Claves: Descriptores: Inmigración, Latinoamérica, inflación, economía y vivienda.

\section{Introducción}

Uno de los problemas sociales con mayor auge en los momentos actuales tiene que ver con la inmigración vista desde un punto de vista sociológico que implica agrandes y pequeños desplazamientos de personas de un lugar a otro y que conlleva un cambio de residencia de manera definitiva o temporal.

Estos desplazamientos hacia los países que lo reciben toma un nombre poco común "Inmigración" que es la llegada de nuevos forasteros al lugar ya habitado, dejando su propio terruño a expensas de enfrentarse a una serie de problemas en su transitar, con sueños y esperanzas de conseguir días mejores. La inmigración toma más sentido en los últimos años dentro de nuestra región.

Según CEPAL (2014) cerca de 28,5 millones de latinoamericanos y caribeños viven fuera de sus países de origen en fin los grandes sin sabores de la realidad política vigentes de hoy en día; una económica globalizada, una sociedad que sufre a diario y una fuerte agresión cultural son ciertas razones que obligan su salida.

Ilustrar ciertos fenómenos que motivan su escapatoria de seres humanos es necesario. A su vez recalcar los efectos que produce a la sociedad donde llega, en especial el Ecuador. Estas explicaciones darán cuenta de este fenómeno que se vinculan con la pobreza y constituye el principal factor de expulsión por su peso histórico y por la grave situación de desigualdades y precariedades económicas, la falta de trabajo, la persecución político-ideológica, la inseguridad producto de la violencia, los problemas sociales, el mejoramiento de la calidad de vida, la búsqueda de desarrollo individual o familiar, acogida familiar, "Turismo, Convenios culturales" oportunidades de empleo y educación, acceso a bienes y servicios, entre otras.

Bajo esta perspectiva enunciaré ciertas causas que inciden en la mayor parte de los países latinoamericanos:

Conflictos políticos las doctrinas políticas queriendo afianzar un modelo que permita la sociedad prosperar económicamente han creado zozobra social y un desequilibrio psicológico de apoyo o rechazo al líder político. Aunque no existe una beligerancia en una determinada zona, si se observa que ciertos países estén sometido a un régimen dictatorial y hostigue sistemáticamente a sus opositores o a un determinado grupo social al no estar de acuerdo con sus preceptos políticos, hace que consigan muchas inmigrantes cartas de refugiados a asilados. Como se cita en ACNUR (2016). 
Sumada a la arrogancia política de ciertos líderes, antecede políticas externas de bloqueos económicos imperialistas, desabasteciendo los mercados y agravándose el desempleo. Provocando una crisis económica aguda y elevando la inflación que no permite a la sociedad mantener su poder adquisitivo.

Falta de oportunidades miles de personas no tienen acceso a una educación de calidad. A un trabajo digno o muchos profesionales que desempeñan una función sesgada a su perfil, hace que decidan emprender nuevos horizontes.

De esta forma, muchas personas pueden buscar trabajo en países donde el mercado sí solicite a profesionales de su área y, de esta forma, poder ejercer la labor para la que previamente se formaron LIFEDER.COM (2010 pág. 1.)

Razones académicas y familiares de los Inmigrantes que salieron con anterioridad a los problemas actuales y tienen las oportunidades que nunca tuvieron en su tierra natal deciden acoger y reunir a las familias por su propia voluntad.

Consecuencias de la migración los seres humanos se ven obligados a abandonar su zona de comodidad y emigrar, sufren un nivel psicológico alto desde el momento de su partida, durante y establecimiento al lugar de destino. Estos pueden ser leves o fuertes; puede ocasionar, angustia, depresión crisis de pánico, congoja desórdenes alimenticios o muchas otras situaciones, dependiendo de su actitud y contacto con los lugareños. A su vez para los lugareños incertidumbre, estigmatización, estereotipos y distanciamiento de los foráneos Aruj, R. (2008).

Rara vez se puede visualizar que el país de acogida crezca económicamente ya que el nivel socioeconómico de los países de la región es similar. Más bien ciertas plazas de trabajo son ocupadas por los inmigrantes dejando a un lado el trabajo que los locales no desean, permitiendo que la economía fluya y se mantenga de manera constante. Por otra parte, se visualiza que sus tareas lo realizan al margen de los derechos laborales.

Dependiendo desde el punto de vista social, el bagaje cultural que ellos poseen puede verse como un enriquecimiento a la cultura propia o como una amenaza a la misma. La xenofobia, es decir, el rechazo al extranjero está extendida en la sociedad debido a los escasísimos acontecimientos sucedidos.

En cualquier caso, existen innumerables ejemplos de países que han acogido a grupos poblacionales muy disímiles y que se han adaptado a él, incorporando sus elementos culturales en el quehacer diario del lugar de acogida. 
Reformas Laborales y económicas de los ministerios que se vuelven obedientes acatando pedido de órganos bilaterales, al ajustar sus políticas para el cumplimiento permanente del pago de su deuda externa, perjudicando a la sociedad a través del achicamiento del estado, paquetes económicos, inversiones extranjeras directas sin revisión legal de requisitos, no intervención del estado en empresas multilaterales, etc.

\section{Metodologia.}

Según Naresh K. Malhotra, las encuestas son entrevistas con un gran número de personas utilizando un cuestionario prediseñado. Según el mencionado autor, el método de encuesta incluye un cuestionario estructurado que se da a los encuestados y que está diseñado para obtener información específica

La metodología propuesta se basa en la investigación de campo aplicando una encuesta a los 200 cuidadanos ecuatorianos de la provincia de Santa Elena.

Modelo de la encuesta. Los tipos de encuestas según los fines científicos, el objetivo principal de la investigación, exploratorias, descriptivas, Explicativas, predictiva, evaluativa, los tipos utilizados en la investigación son descriptiva y evaluativa.

¿Cuáles son los inmigrantes con más porcentaje en la sociedad ecuatoriana de la península?

Venezolanos ( )

Colombianos ( )

Peruanos ( )

Argentinos ( )

¿Cuál es la consecuencia que más afecta a la sociedad ecuatoriana de la Península por el ingreso de inmigrantes?

Desempleo ( )

Vivienda

Educación ()

Alimentación ()

3.- ¿Cree usted que la delincuencia, sicaritos y secuestros de los inmigrantes afectan a nuestra sociedad ecuatoriana?

SI ( )

$\mathrm{NO}($ )

4, ¿Cree usted que la inmigración latinoamericana influye en el desempleo de la sociedad ecuatoriana?

SI ( )

NO ( ) 


\section{Resultados}

Mediante la aplicación de la encuesta se obtuvieron los siguientes resultados.

Tabla No 1. ¿Cuáles son los inmigrantes con más porcentaje en la sociedad ecuatoriana de la península?

\begin{tabular}{lll}
\hline Pregunta No 1 & Numero cuidadanos & Porcentaje \\
\hline Venezolanos & 100 & $50 \%$ \\
Colombianos & 50 & $25 \%$ \\
Peruanos & 20 & $10 \%$ \\
Argentinos & 30 & $20 \%$ \\
\hline
\end{tabular}

Elaborado por: Grupo de Investigación

Gráfico No1: Tipo de inmigrantes.

\section{Tipo de inmigrantes}

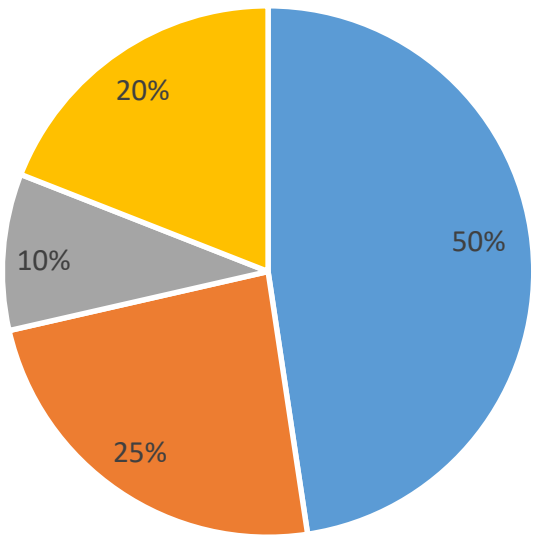

$$
\text { - Venezolanos - Colombianos } \quad \text { Peruanos Argentinos }
$$

Elaborado por: Grupo de Investigación

Análisis: El 50\% de los cuidadanos encuestados manifiesta que porcentaje más alto de inmigrantes es la comunidad venezolana, el $25 \%$ son colombianos, el $20 \%$ argentinos y el $10 \%$ peruanos. 
Tabla No 2. ¿Cuál es la consecuencia que más afecta a la sociedad ecuatoriana de la Península por el ingreso de inmigrantes?

\begin{tabular}{lll}
\hline Pregunta No 1 & Numero cuidadanos & Porcentaje \\
\hline Desempleo & 150 & $75 \%$ \\
Alimentación & 30 & $15 \%$ \\
Educación & 10 & $5 \%$ \\
Vivienda & 10 & $5 \%$ \\
\hline
\end{tabular}

Elaborado por: Grupo de Investigación

\section{Gráfico No2: Consecuencia por la inmigración.}



Elaborado por: Grupo de Investigación

Análisis: El 75\% de los cuidadanos encuestados manifiesta que el desempleo es la consecuencia más alta por ingreso de inmigrantes a la provincia. el 15\% es la alimentación, el $5 \%$ es vivienda y educación. 
Tabla No 3. ¿Cree usted que la delincuencia, sicaritos y secuestros de los inmigrantes afectan a nuestra sociedad ecuatoriana

\begin{tabular}{lcc}
\hline Pregunta No 1 & Numero cuidadanos & Porcentaje \\
\hline SI & 180 & $90 \%$ \\
NO & 20 & $10 \%$ \\
\hline
\end{tabular}

Elaborado por: Grupo de Investigación

Gráfico No 3: delincuencia, sicaritos y secuestros por parte de inmigrantes

Delincuencia y actos ilicitos.

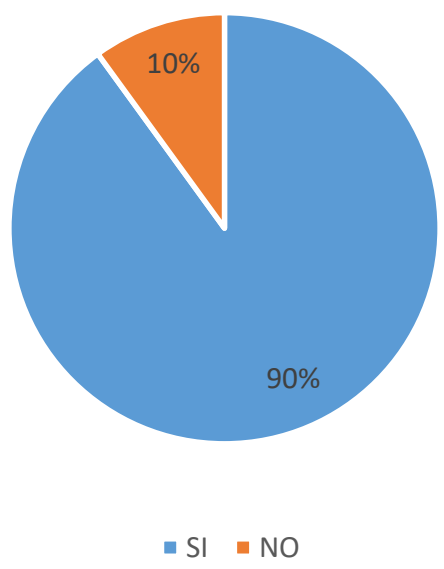

Elaborado por: Grupo de Investigación

Análisis: El 90\% de los cuidadanos encuestados manifiesta que el ingreso de inmigrantes influye en la delincuencia, sicarito y secuestro, mientras del 10\% menciona que no, 
Tabla No $4_{i}$ Cree usted que la inmigración latinoamericana influye en el desempleo de la sociedad ecuatoriana?

\begin{tabular}{lll}
\hline Pregunta No 1 & Numero estudiantes & Porcentaje \\
\hline Si & 185 & $92.5 \%$ \\
No & 15 & $7.5 \%$ \\
\hline
\end{tabular}

Elaborado por: Grupo de Investigación

Gráfico No 4: La inmigración latinoamericana influye en el desempleo de la sociedad ecuatoriana?

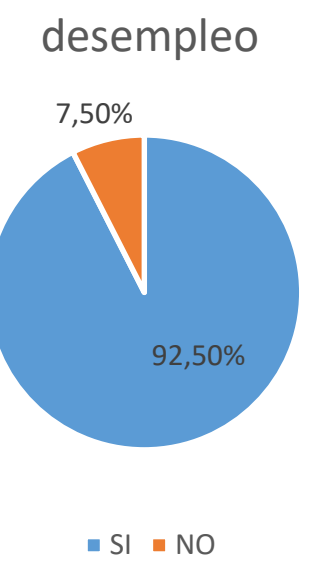

Elaborado por: Grupo de Investigación

Análisis: El 92.5\% de los cuidadanos encuestados manifiesta que el ingreso de inmigrantes influye el desempleo de la sociedad ecuatoriana de la Península, porque el inmígrate por conseguir empleo reduce el salario y el empresario valora al extranjero.

\section{Conclusiones.}

- Se determina que el $75 \%$ de los cuidadnos de la península pierde su trabajo por motivo de que los empresarios valoran el trabajo y sueldo reducido de un inmigrante latinoamericano, esto influye en el desarrollo de la sociedad ecuatoriana.

- Se establece que el $90 \%$ de los cuidadanos de la provincia manifiestan que la delincuencia, sicaritos, secuestros son parte inherente de los inmigrantes latinoamericanos, 
- Se identifica que los inmigrantes influyen en el desempleo de los cuidadanos de la península, porque viene a trabajar con sueldos reducidos y necesidad familiar dejando de lado el tiempo y salarios que normalmente se paga en Ecuador.

\section{Referencias bibliográficas.}

(Aruj, 2008, pág. 14). Causas, consecuencias, efectos e impacto de las migraciones en Latinoamérica. Papeles de población, 14(55), 95-116. Recuperado de scielo.org.mx.

(Acnur, 2016, pág. 01) Diferencia entre refugiado y asilado. Diferencia entre.

Recuperado de diferencia entre.

(Cepal, 2014)

(Lifeder.com, 2010) causas y consecuencias de la inmigración 


\section{PARA CITAR EL ARTÍCULO INDEXADO.}

Toapanta Ulcuango, B., Merino Narváez, W., Campos Cárdenas, F., \& Merino Narvaez, A. B. (2019). La inmigración latinoamericana y su influencia en la sociedad ecuatoriana de la provincia de Santa Elena. Ciencia Digital, 3(2.6), 180-189. https://doi.org/10.33262/cienciadigital.v3i2.6.526

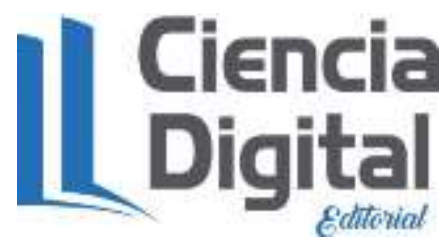

El artículo que se publica es de exclusiva responsabilidad de los autores y no necesariamente reflejan el pensamiento de la Revista Ciencia Digital.

El artículo queda en propiedad de la revista y, por tanto, su publicación parcial y/o total en otro medio tiene que ser autorizado por el director de la Revista Ciencia Digital.
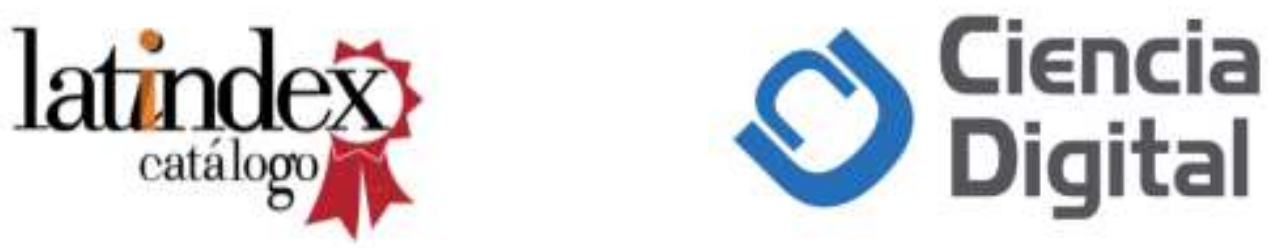